\title{
"It feels as if time has come to a standstill": Institutionalised everyday lives among youth with a mental illness
}

Malene Lue Kessing

Signe Ravn

This is the accepted version of the article, ie the final version before layout and typesetting. Some minor changes may have occured in the proof stages.

The full reference is: Kessing, M. \& Ravn, S (2017): "'It feels as if time has come to a standstill": Institutionalised everyday lives among youth with a mental illness', Journal of Youth Studies, vol. 20(8), pp. 959-973.

https://doi.org/10.1080/13676261.2016.1273523

\begin{abstract}
This paper focuses on the everyday lives of young people with a severe mental illness living temporarily at a social psychiatric housing facility in Denmark. In the paper we take a temporal approach to the analysis of this and we draw on Henri Lefebvre's work on rhythm analysis to investigate the differences between the rhythms of everyday life within the institution and the rhythms of what is perceived as the everyday life of 'ordinary' youth. We also show how digital technologies play a central part in these institutionalised everyday lives by creating connections as well as disruptions between different temporalities and temporal spaces. Centrally, we point to the positive and negative consequences this has for the young peoples' sense of self. Empirically, the paper is based on a four months ethnographic fieldwork at the housing facility in 2014.
\end{abstract}

Keywords: identity; health; sociology of time; everyday life; institutionalisation 


\section{Introduction}

In this paper, we explore how time and self are intertwined within the everyday lives of young people with a mental illness living in a 'total institution' (cf. Goffman 1967). More specifically, we analyse how different temporalities within the institutional setting and beyond interact to create challenging everyday lives and how the young people's 'time work', online as well as offline, can also be seen as 'identity work'. Empirically, the paper is based on a four month ethnographic fieldwork among young people with severe mental illness living temporarily in a social psychiatric housing facility in Denmark.

Despite the recent growth in youth mental illness across a number of Western countries (Eckersley 2008, 2009; Sweeting et al. 2010), knowledge about young people's experience of the challenges following institutionalisation is still limited. Sociological research in this field has predominantly focused on non-institutionalised youth and how they experience and negotiate illness-related stigma in social interactions (Hinshaw 2005; Leavey 2005; Moses 2009, 2010; Whitley and Campbell 2014) as well as their understanding of the illness and their management strategies (O’Reilly 2009; Issakainen and Hänninen 2016; Honkasilta, Vehmas, and Vehkakoski 2016). Institutionalised children and young people have been in focus of research within the health sciences, but from a more instrumental point of view. For instance, researchers have looked at the specific needs of young people who are institutionalised, such as long-term hospitalised children and youth and their need for ongoing educational engagement (e.g. Hopkins et al. 2014; Ferguson and Walker 2014), or the lack of attention on young people's specific needs within health services, especially in relation to transition out of care and interactions with medical staff (Yates, Payne, and Dyson 2009). However, the research to date seems to overlook the more identity-centred challenges 
that young people experience when institutionalised as well as their attempts at managing these challenges. This paper contributes to filling this gap.

The institution in which the fieldwork was conducted can be seen as what Goffman termed a 'total institution', i.e. an institution in which all aspects of life - sleep, work and play - take place in a highly regulated manner, resulting in people leading enclosed lives cut off from the wider community for a considerable amount of time (Goffman 1967). This seminal work set a direction for generations of scholars to follow (see e.g. Rosenhan 1973; McCorkel 1998; Gubrium and Holstein 2000, 2001; Gubrium and Järvinen 2014). Within this 'sociology of institutions', researchers have investigated how institutionalisation poses a temporal challenge, not least because of the inherent disruption from one's everyday activities and routines. Hence, having too much time on one's hands and little to do with it is a common denominator for patients in hospitals (Calkins 1970) through to inmates in juvenile prisons (Bengtsson 2012). While time and temporality were not initial focal points for the present study, during the fieldwork it became apparent how the low activity level at the institution posed a challenge - for the young residents as well as the fieldworker - and how their 'time management strategies' (see e.g. Calkins 1970; Scarce 2002; Bengtsson 2012; Corvinelli 2012) were not only about 'passing time', but also linked up with the young people's sense of self. These experiences motivated us to investigate the 'rhythm' or temporal 'regime' within the institution and how the residents navigate this.

According to Goffman, living in a total institution entails that most or all communication with the outside is brought to a halt. "Family, occupational and educational career lines are chopped off and a stigmatized status is submitted" (Goffman 1967, 4), having severe consequences for the self. Goffman developed the ideal type of the total institution in the 1950 s and 60 s and obviously a number of changes have occurred since then; changes that 
mean that living in a 'total institution' today is in some aspects different, perhaps especially in relation to the level of contact with the outside world. One such change concerns the 'permeability' of the institution (rather than its 'total' character), meaning that humans as well as artefacts can more easily move in and out of the institution (Quirk and Lelliot 2001; Quirk, Lelliott, and Seale 2006). Another change is of a more socio-cultural character and relates to the advent of digital technologies. This is not least relevant given the young population at the institution in focus in this paper. The residents are not entirely isolated from the surrounding world, but their interaction with this world is predominantly taking place through social media and other digital platforms. While some institutions, e.g. prisons and prison-like facilities, do not allow the residents access to digital technologies such as cell phones and laptops, a wide range of other 'total institutions' (hospitals, treatment facilities, residential care etc.) do, but we know little about how these technologies affect the boundaries between 'inside' and 'outside' and how this plays into young people's everyday experiences of time. To investigate this, we analyse the temporal experience of institutionalised everyday life and how different temporalities - within the institution and beyond - interact and create possibilities as well as challenges for young people living in the institution. In particular, we focus on the links between time and self and we explore how the young residents' 'time work', online as well as offline, is also 'identity work'. Before we present the study in more detail, we briefly introduce the theoretical framework.

\section{Theoretical framework}

In modern societies, time is often thought of as linear and moving in one direction; forward, towards the future (Adam 2004). This is not only the case in popular imagination but also in social theory, dating back to classical social theorists such as Marx, Weber and Simmel (Maines 1987). Furthermore, this approach is also underlying research traditions such as 'life 
course studies' (cf. Giele and Elder 1998); the idea that we move through life from one phase to another with an unavoidable progression - from childhood via youth to adulthood.

However, time is not only linear, but also cyclical. Cyclical time includes not only the daily and annual cycles but also the cycles prescribed by the changing seasons (Lewis and Weigert 1981). The social theorist who has provided the probably most elaborated conceptualisation of cyclical time is the French philosopher Henri Lefebvre (2004), whose work on 'rhythmanalysis' uses the familiar concept of a rhythm to emphasise the importance of a cyclical and repetitive approach to time in everyday life.

Seeing everyday life as consisting of (a multitude of) rhythms does not imply a mechanistic view of how life unfolds; rhythms are organic and mouldable. Rhythms occur at varying pace and have a duration, for instance the seven days of the week. In addition, different rhythms can co-exist (Bennett 2015), and while compatible rhythms can 'swing together' and even be nested within each other, some rhythms may instead counteract each other. A central aim for Lefebvre was to emphasise how time and space are inter-connected. Rhythms exist when place, time and "an expenditure of energy" come together (Elden 2004, ix), and places are constituted through time, i.e. through the rhythms unfolding there (Bennett 2015). In relation to this paper, this means that we can view the housing institution as constituted by specific rhythms; rhythms that we will explore in detail in the analysis. Studying such rhythms involves, according to Lefebvre, that the researcher engages him- or herself in the rhythm: "To grasp a rhythm it is necessary to have been grasped by it" $(2004,27)$. As we will return to in the Methods section, the first author who carried out the fieldwork also found herself being subsumed by the rhythms of the institution during the fieldwork, at the same time as her position in the field was for a number of reasons different from that of the young residents and allowed for a more distanced approach. 
Lefebvre also emphasised that rhythms can be related to "the imaginary" $(2004,18)$. As we will illustrate, this sometimes seems to be the case when the participants describe the rhythms of 'ordinary' youth life, as this is often depicted in a highly idealised manner - as busy, inspiring and eventful - and in clear contrast to their own everyday life and its slower pace. Brannen and Nilsen (2002), in their research on young people's time perspectives, have used the concept accelerated time to describe how more and more activities - work, consumption, leisure events - are compressed into a still shorter time span, producing a constant sense of busyness and intolerance for waiting. As we will show in the analysis, the young people in this study also express intolerance for the 'waiting' they associate with their stay at the institution, but, importantly, not because they are busy, rather because they are not. While the 'ebb and flow' of the rhythms that Lefebvre described can proceed faster or slower, the rhythm - and hence time - does not stop. However, as will become clear in the analysis, this was exactly what a number of the young residents felt happened at the institution; that their life was involuntarily brought to a halt and they were waiting for it to start again.

Flaherty (1987) describes how the way in which we perceive of time and duration is tied to the social context in which we find ourselves, and when this context changes our temporal consciousness changes as well. Hence, when being institutionalised the young residents have to adjust to the pace of the rhythm at the institution. As we will show in the analysis below, this does not merely cause confusion or frustration, but also challenges them at a subjective level. Flaherty, drawing on the phenomenology of Husserl and Heidegger as well as more constructivist approaches, links the way we experience time to subjectivity: "On the most basic level, then, temporality is an aspect of subjectivity" $(1987,313)$. The feeling of being at 
'a standstill' challenges the young people's sense of self as young people. Following Goffman ([1963] 2009), we can conceptualise these 'halted', young identities as 'spoiled' or stigmatised, but in a slightly different way than proposed by Goffman. Hence, it is not (only) a certain characteristic such as their mental illness that is experienced as stigmatising, but (also) the fact that their everyday life deviates from the (idealised) perceptions of youth as being busy and in motion. Given the methodology of our study we do not know whether this perception extends to their peers or if it is mainly a self-imposed stigma, i.e. an internalisation of experienced stigma (cf. e.g., Corrigan and Watson 2002). Regardless of this, though, it emphasises the moral experience of stigma (Yang et al 2007) and the normativity of conforming to societal time structures (Lewis \& Weigert 1981). Inhabiting a stigmatised identity is discrediting and requires ongoing 'impression management', i.e. techniques through which a person can create, maintain or discredit a specific image of self, both verbally and non-verbally (Goffman 1956) to 'pass as normal'. Hence, in their ongoing identity performances, the young people at the institution employ different strategies, both online and offline, when trying to negotiate a 'normal' self.

In the analysis we take our point of departure in Lefebvre's rhythm analytical approach and combine this with the subjective dimensions of the lived rhythms that we identify in the data. Central in this is a focus on how the young people's time work is also identity work, online as well as offline.

\section{Methods and data}

The paper is based on four months of ethnographic fieldwork at a social psychiatric housing institution for young people with severe mental illness, conducted by the first author from February until May 2014 (cf. Author A 2015). The aim of the study was to investigate the 
young residents' conceptions of being young and living with a mental illness and how they coped with this on a day to day basis while living at the institution. The data covers field notes from extensive participant observation (around 600 hours in total), semi-structured interviews with 10 young residents and 10 employees and two focus groups with young residents. In this paper we mainly draw on field notes and interviews (individual and focus groups) with the young residents.

The housing institution was managed by the local municipality and was based on a social pedagogical approach, not therapeutic or psychiatric treatment. The purpose of the housing facility was to enable the residents to move into an apartment of their own and return to 'ordinary' life. Hence, living at the housing facility was a temporary solution, in principle for no longer than two years, though this was managed with some flexibility in individual cases. The housing facility had a specific focus on developing the residents' day-to-day 'life skills' through activities such as preparing lunch, picking up mail and going grocery-shopping. The staff (most with a background as nursing assistants or social educators) also assisted the residents in managing their illness, for instance in relation to administering medication, cleaning their rooms and attending to personal hygiene. The institution had a maximum of 12 residents, and a staff/resident ratio close to 1:1. Each resident had a 'care plan', developed in collaboration with staff at the time of admission. Depending on the young people's mental condition, weekly or monthly meetings were arranged to discuss their problems and progress in relation to this plan. Therapeutic treatment and medication was handled by the regional psychiatric hospital. The residents were offered housing at the institution through the local municipality, following a hospitalisation at a psychiatric ward. During the fieldwork three residents were re-admitted to the hospital for a few days because their illness worsened. 
Staying at the institution was voluntary and while the staff could terminate the young people's stay if necessary (i.e., if not compliant), they were reluctant to do so.

The residents, 7 women and 5 men, were aged 18-24. Most were diagnosed with schizophrenia and one with personality disorder. All were on different kinds of medication. Many were also diagnosed with ADHD and struggled with self-harm and substance use, primarily cannabis use. None of them were in treatment for substance use problems, and while substance use was not allowed on the premises the staff often did not interfere with this.

Participant observation was carried out 4-5 days a week and supplemented by a full two weeks stay. The individual interviews (10) enabled further exploration of how the young people coped with their illness. These were carried out as biographical interviews, focusing on the young peoples' upbringing, their relation to family and friends, the development of their mental illness and their experiences with living at the institution. The focus group interviews (two groups with the same five participants) enabled an exploration of residents' broader conceptions of being young and living with a mental illness (Kitzinger and Barbour 1999). To facilitate the discussion, the focus groups involved a task asking participants to jot down and later explain specific words that they associated with being young (in the first focus group) and with living with a mental illness (in the second focus group).

Informed consent was obtained from staff as well as 10 out of the 12 young residents. Two residents declined to participate in interviews but did not oppose the fieldworker's presence. However, for ethical reasons they are also left out of the field notes. Participants were 
promised full anonymity, all names are pseudonyms and other identifiable characteristics are changed.

The analytical focus on temporality meant that, for this paper, the first author coded all passages from the field notes and interviews relating to time and temporality. This broad code was coded independently by both authors, focusing on time inside the institution, time outside the institution, connections between the two and the young people's time management strategies. These codes were compared and discussed by both authors.

\section{Analysis}

\section{The rhythms of institutionalised everyday life}

We first consider the everyday rhythms, or the temporal 'regime', that the institutional structure forges and how this is experienced by the residents. The pedagogical approach of the institution involved set day-to-day cycles with various chores as well as specific expectations of personal development. Simultaneously, though, it was framed as a nontherapeutic space, in which the young residents' everyday lives unfolded somewhat like the life of 'ordinary' teenagers (sleeping in, doing housework, watching TV and hanging out with friends). This generated distinct everyday rhythms as the following passage from a field note describing a morning meeting shows:

It is $10 \mathrm{am}$ and we are gathered in the kitchen for the usual morning meeting. Sara, Charlotte and Christian, who live at the institution, are sitting around the table. The other residents are still sleeping even though Hanne, a member of the staff, has encouraged them to get out of bed. The usual list of the daily chores is on the table, ready for the residents to split the tasks between them. 
Sara picks it up and asks who would like to empty the dishwasher today.

Nobody answers. After a while the task is assigned to Frederik, who is still sleeping. Sara continues reading the tasks out loud. These involve preparing lunch and cleaning up afterwards, emptying the trash bin and picking up the mail. Someone also has to prepare dinner, which means heating the food that the institution's in-house chef prepares. After the chores are assigned, the meeting ends at 10.10am and the residents leave the kitchen and go back to their rooms.

According to staff, this structure - daily morning meetings, few and simple chores, communal meals at set times - aimed at generating structure and tranquillity. Morning meetings were mandatory but as the excerpt shows, most residents did not bother or did not have the energy to get up for these meetings. Those who did often assigned chores to those who were absent. While the staff tried to gather all residents by knocking on their doors to remind them of the meeting, they were often unsuccessful in this and without any possible sanctions. Following the morning meeting the daily chores began. Apart from this the residents mostly passed time in their rooms, smoking cigarettes while watching television or listening to music, only interrupted by the 12 o'clock lunch and 6pm dinner served in the kitchen. As pointed out by Lefebvre (2004), every rhythm has a duration and a pace, and as shown the institutional rhythm was made up by few, repetitive daily activities unfolding at a slow pace.

This rhythm was intentional and considered a necessity by staff because of the residents' mental health. Importantly, most residents also acknowledged this and agreed that "it is dangerous to make us do a lot of stuff", as Laura (20, diagnosed with schizophrenia) said. A 
number of residents described incidents of having overdone it. For instance, Sofie (21, diagnosed with schizophrenia) told how she during winter break stayed with her family, visiting tourist attractions and celebrating her birthday. Returning to the institution, she withdrew to her room and had to stay at the institution for two weeks due to increased symptoms of her schizophrenia. Likewise, Laura describes the difficult balance: "when I am feeling well, I start all these different activities. The whole world is spinning [...] and then a couple of days pass, and you come back down. You have been pushing yourself, because you were doing okay, but you just cannot handle it". Thus, the slow pace of the rhythm came to constitute the institution as a 'safe haven', emphasising the interconnectedness of time and space (Elden 2004; Lefebvre 2004). Through this compliance with the institutional rhythms the young people seemed to accept and reproduce the understanding of themselves as not well and in need of tranquillity.

On the other hand, however, the everyday rhythm at the institution also caused frustration. The institutional rhythm set aside time for the residents to attend activities outside of the institution such as school or work, but only three of the 12 residents did so: Mads was about to finish lower secondary school ( $9^{\text {th }}$ grade) in an alternative educational programme, Jonas participated in a cooking and training programme for young people outside of mainstream education, and Sofie did an internship at a local business. Hence, the majority of the residents spend most of their time at the institution. They were free to do what they wanted during the day and could suggest activities or go into town, but given the location of the institution on the fringe of a provincial town they were either dependent on public transport or had to go by bike. In effect, the majority primarily stayed at the institution, left with an abundance of time on their hands and not much to do with it. Charlotte (20, diagnosed with schizophrenia) 
commented on this one day while sitting in the shared area:

While we are playing cards Charlotte explains that she is frustrated with her life: "Life kind of goes in circles. The same things are happening; I get up, drink a Red bull, do not eat, smoke a cigarette, walk around alone or together with Frederik and eat some bread. It is a negative circle and I would like to break free from it". She tells that having to drop out of school because of her illness was hard on her. She was in the second year of high school and completely fell apart. She tells how she now feels that she is a disappointment to everyone around her and that she feels stupid and lazy because she is not doing anything.

For Charlotte, the contrast between her everyday life before and after her diagnosis is not only about how she spends her time, but ultimately about her self-perception and feelings of moral worth. For her, the simple routines and repetitive daily chores at the institution were far from meaningful. Frederik (21, diagnosed with schizophrenia) expressed similar feelings: "Life has come to a standstill. And I do not know if I will ever move on". Frederik had been enrolled in a educational program but had been expelled from this because he could not get up in the morning. Instead he was offered a mentor; an arrangement he was dissatisfied with as he did not see how this would bring him closer to education or a job. For both Frederik and Charlotte then, the developmental intentions inherent in the chores at the institution did not align with the skills and goals they themselves were aiming for; education and ultimately a job. 
Such frustrations with the institutional rhythm were not just practical but had implications for the young peoples' sense of self (cf. Flaherty 1987). In sum, the institutional rhythm produces conflicting temporal experiences and associated ambiguous subjectivities: on the one hand the residents considered themselves as needing tranquillity and a slow pace, while on the other hand the lack of activities and progress questioned their sense of self. This emphasises how everyday life at the institution cannot be understood in isolation from society at large. As we show in the following section, the residents are not cut off from communication with family and peers on the outside; a communication that at times adds to these ambiguities.

\section{Connections and disruptions}

The daily rhythm at the institution co-existed with other rhythms in the young residents' lives. Through internet, social media and cell phones they were connected to family and friends outside the institution and in this section we explore how this creates - social and temporal - connections as well as disruptions that are both empowering and challenging for the residents' temporal experiences and sense of self.

Few residents had regular face-to-face contact with friends outside the institution but stayed connected, primarily through SMS texting or Facebook. According to Wang and Edwards (2016), social media generally create a space within which highly reflexive relationships and self-projects are produced and maintained. For the participants in this study, this form of interaction made it possible for them to, to some extent, exert control over how much of surrounding society they would allow into the institution and their everyday life. They could also negotiate their degree of online participation and visibility (Berriman and Thomson 2015). Asked what she used Facebook for, Sara (20, diagnosed with schizophrenia) said that "it is to stay updated. It is instead of a newspaper, it is a 'Facepaper"'. While some of the 
residents were mainly 'low participation' users (Berriman and Thomson 2015) of Facebook, using it to stay up to date with their friends' lives, like Sara, a number of them also used Facebook more actively, for instance to upload pictures from activities they attended:

Going to the zoo with Laura one day she asked for a picture of me [first author] and her that she then uploaded to Facebook accompanied by a text explaining that she was in a great mood. Later, she turns to me, smiling: "Everybody is "liking" our picture from earlier”.

By uploading the photo to Facebook Laura connects to what she perceives as the temporality of 'ordinary' young people's everyday life, i.e. a busy, eventful and social life. Through this she presents herself as a 'normal' young person; a sense of self that is confirmed through the 'likes' that the picture gets online. By 'liking' and commenting on other people's posts, and by receiving 'likes' and comments themselves, the young residents actively engaged in a virtual world unfolding in different social and temporal spaces than at the institution. While this allowed Laura to feel empowered and connected, the sheer difference in the number and nature of her updates compared to those of her friends also underlined her own very different life situation, and the slower pace of this, compared to that of her friends; a disruption we return to below.

Some online spaces allowed connections beyond the institutional setting through a more radical, 'selective' presentation of self than Facebook. Thus, one of the main attractions of online gaming for Christian (22, diagnosed with schizophrenia), was the fact that he would never meet the other players face-to-face and the opportunities this provided in terms of managing his online identity. Christian said: "I am playing with someone who does not know 
that I live here [at the institution]. If they knew, they might think that I'm weird. I don't see them privately, but I have played with them for a long time”. To sustain this image of being an 'ordinary' young person, Christian denied staff members access to his room while playing. In that sense, Christian's 'impression management' (Goffman 1956) also included his immediate environment in the 'digital body' he constructed (boyd 2007). By establishing connections with young people in different time-spaces, Christian can, if only temporarily, transcend the institutional boundaries and thereby his everyday life and sense of self as it unfolds here.

As the examples with Christian and Laura above show, being able to stay connected and to present oneself, and have a sense of self, as an 'ordinary' young person were central motivations for online interactions. But these online interactions also generated disruptions in the young peoples' everyday life and sense of self. Given their lack of regular face-to-face contact with peers, social media was one of their primary sources of information on what this 'ordinary' life looks like, while reality TV such as 'Paradise Hotel' (depicts a group of young people living at a hotel resort and competing about who stays the longest while partying, drinking alcohol, flirting and having sexual relationships etc.) was another. Identifying with 'media others' allows us to experience social reality from other perspectives (Cohen 2001), but this social reality may be somewhat partial and depict the lives of 'ordinary' youth in an idealised way. Hence, when asked in a focus group interview about what this 'ordinary' youth life consists of, the participants mentioned aspects such as partying every weekend, being enrolled in education, travelling and seeing the world and moving out of their parents' home. In short, in Laura's words, 'life would be on a roll'; they would be on the move, literally and not least figuratively speaking. The temporal disconnection they experienced not 
only concerned the slower pace of the rhythms at the institution, but also the lacking sense of progression:

Mads: It can also be stressful to not do anything.

Laura: Exactly, I mean, I imagine that is really stressful for all of us [...] Like, you get really frustrated and completely stressed about 'why am I not studying, why don't I have a job?'

Mads: So being young is stressful for us as well, even though we are doing nothing.

Interviewer: Okay, it's stressful even though you are not busy doing these things. Why is that so?

Laura: Because you want to.

Frederik: You want to, but you can't.

Charlotte: I just feel that life has come to a standstill.

Frederik: It was just 'full speed ahead' before you came here. Before you were hospitalised or whatever.

Laura: I think that if you are young, without a mental illness like us, then yes, it would be stressful. But I don't think that things would have come to a halt. And I don't think they are frustrated in the same way because they are in motion. They can see their life moving forward.

What becomes clear here is how the feeling of not being busy but being at a "standstill", or in other words the feeling of being disconnected from the rhythm of ordinary youth life, both in terms of pace and direction, causes frustration and stress. The young peoples' experience of time and everyday life at the institution is compared to and measured against specific cultural 
expectations related to being young; expectations that include a constant sense of busyness as well as intolerance for waiting (cf. Brannen and Nielsen 2002). This feeling of being disconnected from 'ordinary' youth lives became especially evident when Facebook friends did not respond to a message; something the young residents often took as a dismissal of their friendship. The quote above also pinpoints how temporality and identity are closely linked: the temporal disconnection challenges the residents' sense of self as young people. While rhythm analysts emphasise how different rhythms can 'swing' together (e.g. Bennett 2015), the example here shows how the rhythms or ordinary youth life and everyday life at the institution did not do so; rather they seemed to be disconnected from one another and constitute two very different time-spaces. These were primarily connected through technologies such as social media, and with ambiguous outcomes. Social media and digital technologies enable connections to other temporalities, or other time-spaces, at the same time as they come with a temporality of their own, illustrated for instance in response times and the amount of new updates. Hence, while these platforms facilitated connections to people outside the institution, they also created multiple disruptions of the temporal rhythm inside the institution. These temporal connections and disruptions also worked in complex ways to affect the residents' sense of self both positively and negatively.

\section{Negotiating time, negotiating identities}

In the above sections we have shown how the rhythms of the institution constitute both a 'safe haven' as well as a time-space that challenges the residents' sense of self as young people because of the disconnection with the (perceived) rhythm or ordinary youth life. We have shown how not only the time structure of the institution but also of life outside the institution, mainly mediated through digital technologies, are imposed on the residents' everyday lives. However, the young residents are not simply subject to these time structures. 
They actively engage in negotiating their temporal experiences and sense of self, not least through social media. While e.g. Facebook on the one hand highlights the contrast between their situation and the everyday lives of non-institutionalised youth, being active on this platform is simultaneously a way of 'passing' time and, more importantly, a way of negotiating their sense of self. For instance, by selectively posting pictures from 'ordinary' activities or, as in Christian's case, only revealing certain bits of information about themselves, they are able to challenge the 'stigmatised' identity others may ascribe them.

Such negotiations of time and identity were not restricted to online spaces but also occurred offline. At the institution this could for instance involve moving furniture around or drinking alcohol in their rooms; activities that were not allowed but which nevertheless served to pass time, be active, change their temporal perceptions and place themselves in opposition to the (adult) staff and their rules. At other times the residents arranged activities outside the institution, most often going out at night in the nearby town. The excerpt below is from one of those nights out, where the first author accompanied a group of five young people - Mads, Frederik, Laura, Marie and Peter - to the local town. Before going out, they went predrinking at Mads' brother's place. On the bus into town everyone's mood was good. Frederik and Mads were joking with each other, when suddenly Marie did not feel well:

Marie tells me she wants to go home. She is not feeling well. The two of us get off the bus at the station and wait for the next bus home, while the others continue to a bar. Marie tells me that she was feeling really paranoid. She thinks this is why her hands were shaking, when we were at Mads' brother's place; because it was coming. I ask how it feels. Marie says that she felt that something bad would happen if she did not get home. She explains that this is just how it is when they 
go out: "If we had stayed for longer, Mads would have started being paranoid as well". I say that it was fun to go out with them, even though we had to go back home early. Marie says "Yes, yes, when we are out we are like normal young people”. On the bus back to the institution she tells me that she is feeling better, because we are getting closer to home, and because this means that she feels secure. When we arrive at the institution, Marie goes to the main office to let the staff know that she is back and that she is not feeling well.

The episode pinpoints the complexity and ambivalence that is characteristic of the young people's everyday life at the institution. By leaving the 'denormalising' institutional space and doing what 'ordinary' young people (are perceived to) do, i.e. go out and party, the residents try to combat the feeling of being at a standstill - and thereby the feeling of not being young. However, as also becomes clear, both efforts are complicated by their severe mental illnesses. Importantly, though, even though Marie had to return to the 'safe haven' of the institution earlier than planned she still emphasised how moments like this enabled all of them to feel, and be seen by others, as "normal young people", if only for a night. This highlights the identity work that is entailed in 'time work'; the residents' efforts at negotiating and sometimes opposing the temporal structures they encounter - and their inherent subjectivities - allows them to perform and present other selves, sometimes just temporarily. By highlighting the young peoples' different ways of challenging temporal structures and connecting with 'ordinary' youth life it becomes evident how online and offline spaces offer different opportunities through which the young residents can negotiate time as well as sense of self, and how these two spaces pose different challenges in relation to the young peoples' everyday lives and mental illness. 


\section{Discussion}

In the analysis we have shown how different temporalities within and beyond the institutional setting co-existed and how these different temporalities created opportunities as well as challenges for the young residents. Considering the institutional rhythm, it was apparent that this on the one hand constituted a 'safe haven' for the young people; a time-space they could withdraw to when their illness necessitated this, in large part due to the slower pace of the rhythms constituting this space. On the other hand the lack of activities and progress questioned their sense of self causing regular frustrations and the slower rhythms at the institution therefore also came to be a reminder of them being at a "standstill". Barbara Adam notes how various cultures for centuries have sought to transcend time; to "make time stand still, to create permanence in the sea of change" $(2004,76)$, for instance through myths and rituals. For the young people here, though, this was not something positive that they actively strived for, but rather a negative consequence of their illness and institutionalisation that was troubling in relation to their perception of 'ordinary' (non-institutionalised and not ill) youth. This highlights how the contrast between the temporal rhythm of the institution and the cultural understandings of how life as a young person looks made it hard for them to identify as 'normal' young people (cf. Brannen \& Nilsen 2002).

A number of scholars have described how institutionalisation, whether in settings as different as prisons (Bengtsson 2012) and hospitals (Calkins 1970), interrupts the individual's routines and rhythms and calls for time management strategies. We can view the young residents' use of social media, their nights out and their oppositions to 'house rules' within the institution as one such time management strategy aiming at connecting everyday life inside the institution with other temporalities and social spaces; if only temporarily. However, this was not simply a strategy to manage time but also an attempt at maintaining an identity as young people; 
their 'time work' was also identity work. Following Goffman, institutionalisation involves a removal of peoples' positive self-identification through which their self becomes aligned with that of a stigmatised person. While the institution does not seem to offer any age-specific positive points of identification for the residents, digital technologies offered the most prominent means for challenging their 'moral experiences' (cf. Yung et al 2007) of being 'deviant'. Hence, we saw how digital platforms allowed selective, positive self-presentations and how these features were used strategically to avoid the (perceived) stigma associated with being young and having a mental illness (Leavey 2005; Moses 2010). In addition, digital platforms also provided the residents with a private space that was off limits for staff, and compared with face-to-face interactions it allowed them more time to prepare and filter statements, questions and responses; a feature that for some was very comforting. These aspects notwithstanding though, digital technologies were not simply positive and empowering. On the contrary, they also came to highlight the temporality of life 'on the outside' (or a version of it) and thereby the contrast between this and the institutionalised everyday life of the residents. Digital technologies can be seen as permeating the institution's borders - and disrupting the institutional rhythm and the sense of self bound up in this. In that way, understanding the interplay between the temporality of the institution, and the 'offline' identity associated with this, and the temporalities displayed through online spaces, and their associated identities, becomes central.

While early research tended to view online and offline spaces as separate, more recent work suggests that "online identities are considerably more intertwined and consistent with [their] offline identities" (Davis 2014, 16, see also Robards 2012) than previously assumed. This also seems to hold true for many of the participants in this study, with the exception of Christian who performed a fairly different - non-ill - identity online. The majority of the 
participants used social media mainly to stay in touch with friends outside of the institution, i.e. people who for the most part knew (more or less) about their mental illness and 'disconnecting' their offline and online lives was in that way not an option, even if they had wished to distance themselves from the stigmatised or 'flawed' identity of a young person with a mental illness. Instead, the young residents' online identity work can be seen as a negotiation of what this stigmatised identity as a young person with a mental illness entails. For instance, posting pictures from 'ordinary' activities highlights the 'normalcy' of their everyday lives. In that way, digital technologies such as social media become a way of negotiating the stigmatised identity, in some cases even by embracing it through status updates about 'feeling down' or 'being sad'. Importantly, as illustrated in the analysis, such negotiations not only took place online but also offline, both within and beyond the institutional setting.

Our analysis and discussion above suggest that Goffman's ideal type of a total institution needs some adjustments to capture not only the characteristics of the particular institution in focus here, but also to accommodate the conditions posed by the 'omni-presence' of social media. Sian Lincoln, speaking on the basis of her research on girls' bedroom cultures, argues that technologies such as cellphones, TV and social media change these private spaces into mediated and fluid constructions (Lincoln 2004). Applying these insights to our focus on institutions, we suggest viewing these as even more permeable than suggested by Quirk and colleagues (2006). In terms of the everyday lives of the young people in this study, we have shown how such fluidity is not without challenges, especially bearing in mind that the young people's mental illnesses pose an additional layer of complexity. As became clear in the analysis, staff as well as residents agreed on the need for tranquillity and therefore also of the slow pace of the institutional rhythm; a pace that challenged the young people's ability to 
perform an identity as young people. What this study points to, then, is a challenge in the organisation of institutions such as the one in focus here, and most likely other residential institutions for young people, but also a potential way forward in the sense of utilising the fluid character of the institution in ways that support the residents' need for creating connections beyond the institutional setting and performing identities as young people, while still taking their mental illness into account. One such way forward could be a greater use of online educational resources and perhaps even formal online programmes, now offered by many educational institutions. These often allow students to study at their own pace and can thereby accommodate fluctuations in mental health, while at the same time providing a feeling of progression and alignment with (parts of) the lives and activities of 'ordinary' youth; critical aspects for the overall well-being and identities of institutionalised youth. 


\section{References}

Adam, B., 2004. Time. Polity Press: Cambridge.

Bengtsson, T. 2012. "Boredom and Action - Experiences from Youth Confinement". Journal of Contemporary Ethnography 41 (5): 526-553. doi:10.1177/0891241612449356.

Bennett, J. 2015. “'Snowed In!’: Offbeat Rhythms and Belonging as Everyday Practice”. Sociology 49 (5): 955-969. doi:10.1177/0038038515589299.

Berriman, L., and R. Thomson. 2015. "Spectacles of Intimacy? Mapping the Moral Landscape of Teenage Social Media”. Journal of Youth Studies 18 (5): 583-597. doi:10.1080/13676261.2014.992323.

boyd, d. 2007. Why Youth (Heart) Social Network Sites: The Role of Networked Publics in Teenage Social Life. MacArthur Foundation Series of Digital Learning - Youth , Identity, and Digital Media Volume. Cambridge, MA: MIT Press.

Brannen, J., and A. Nielsen. 2002. "Young People's Time Perspectives: From youth to adulthood”. Sociology 36 (3): 513-537. doi:10.1177/0038038502036003002.

Calkins, K. 1970. “Time: Perspectives, making and style of usage”. Social Problems 17 (4): 487-501. doi: $\underline{10.2307 / 799681}$

Cohen, J. 2001. "Defining Identification: A Theoretical Look at the Identification of Audiences With Media Characters”. Mass Communication \& Society 4 (3): 245-264. doi:10.1207/S15327825MCS0403 01

Corrigan, P.W., and Watson, A.C. 2002. The paradox of self-stigma and mental illness. Clinical Psychology: Science and Practice 9 (1): 35-53. doi:10.1093/clipsy.9.1.35

Corvinelli, A. 2012. "Boredom in Recovery for Adult Substance Users With HIV/AIDS Attending an Urban Day Treatment Program". Occupational Therapy in Mental Health 28 (3): 201-319. doi:10.1080/0164212X.2012.708643 
Davis, J. 2014. “Triangulating the Self: Identity Processes in a Connected Era”. Symbolic Interaction 37 (4):500-523. doi:10.1002/symb.123

Eckersley, R. 2008. Never Better or Getting Worse? The Health and Wellbeing of Young Australians. Canberra: Australia 21.

Eckersley, R. 2009. “The Health and Well-Being of Young Australians: Patterns, Trends, Explanations and Responses". In Challenges in Adolescent Health: An Australian Perspective, edited by D.L. Bennett, S.J. Towns, E.L. Elliott, and J. Merrick, 3-19. Nova Science: New York.

Elden, S. 2004. "Rhythmanalysis: An introduction". Introduction in Lefebvre, H. (2004). Rhythmanalysis. Space, Time and Everyday Life. London: Bloomsbury, pp. vii-xv.

Ferguson, P., and H. Walker. 2014. “"Getting on with Life': Resilience and Normalcy in Adolescents Living with Chronic Illness". International Journal of Inclusive Education 18 (3): 227-240. doi:10.1080/13603116.2012.676082

Flaherty, M.G. 1987. "Multiple Realities and the Experience of Duration”. The Sociological Quarterly 28 (3): 313-326. doi:10.1111/j.1533-8525.1987.tb00297.x

Giele, J.Z., and G.H. Jr. Elder. 1998. Methods of Life Course Research: Qualitative and Quantitative Approaches. London: Sage Publications.

Goffman, E. 1956. The Presentation of Self in Everyday Life. University of Edinburgh: Social Science Research Centre, monograph no. 2.

Goffman, E. [1961] 1967. Anstalt og Menneske. København: Jørgen Paludans Forlag.

Goffman, E. [1963] 2009. Stigma. Om Afvigerens Sociale Identitet. Frederiksberg: Samfundslitteratur.

Gubrium, J. F., and J.A. Holstein. 2001. Institutional Selves. Troubled Identities in a Postmodern World. New York: Oxford University Press. 
Gubrium, J.F., and J.A. Holstein. 2000. "The Self in a World of Going Concerns". Symbolic Interaction 23 (2): 95-115.

Gubrium, J.F., and M. Järvinen. 2014. Turning Troubles into Problems: Clientization in Human Services. London: Routledge.

Hinshaw, S. 2005. "The Stigmatization of Mental Illness in Children and Parents: Developmental Issues, Family Concerns and Research Needs". Journal of Child Psychology and Psychiatry 46 (7): 714-734. doi:10.1111/j.1469-7610.2005.01456.x

Honkasilta, J., S. Vehmas, and T. Vehkakoski., 2016. "Self-Pathologizing, Self-Condemning, Self-Liberating: Youths' Accounts of their ADHD-Related Behavior”. Social Science \& Medicine 150: 248-255. doi:10.1016/j.socscimed.2015.12.030

Hopkins, L., J. Moss, J. Green, and G. Strong, G. 2014. "Embedding Learning in a Pediatric Hospital: Changing Practice and Keeping Connected”. International Journal of Inclusive Education 18 (3): 312-321. doi:10.1080/13603116.2012.752877

Issakainen, M., and V. Hänninen. 2016. "Young People's Narratives of Depression”. Journal of Youth Studies 19 (2): 237-250. doi:10.1080/13676261.2015.1059927

Järvinen, M. and S. Ravn (2017): "Out of sync: Time management in the lives of young drug users". Time \& Society, early online.

Kessing, M.L. 'Det er lidt, som om livet er gået i stå'. En antropologisk undersøgelse af ungdomsliv, identitet og fremtidsdrømme på et midlertidigt botilbud. Kandidatspeciale. København: Institut for Antropologi.

Kitzinger, J., and R. Barbour. 1999. "Introduction. The Challenge and Promise of Focus Groups”. Introduction in Developing Focus Group Research. Politics, Theory and Practice. London: SAGE.

Leavey, J. 2005. "Youth Experiences of Living with Mental Health Problems: Emergence, Loss, Adaption and Recovery (ELAR)”. Canadian Journal of Community Mental Health 24 (2):109-126. doi:10.7870/cjemh-2005-0018

Lefebvre, H. 2004. Rhythmanalysis. Space, Time and Everyday Life. London: Bloomsbury. 
Lewis, J.D., and A.J. Weigert. 1981. "The Structures and Meanings of Social Time”. Social Forces 60 (2): 432-462. doi:10.2307/2578444

Lincoln, S. 2004. “Teenage Girls' 'Bedroom Culture’: Code versus Zones”. In After subculture: critical studies in contemporary youth culture, edited by Bennett, A., and K. Kahn-Harris. London: Palgrave/Macmillan, pp. 94-106.

McCorkel, J.A. 1998. "Going to the Crackhouse: Critical Space as a Form of Resistance in Total Institutions and Everyday Life". Symbolic Interaction 21(3): 227-252. doi:10.1525/si.1998.21.3.227

Maines, D.R. 1987. “The Significance of Temporality for the Development of Sociological Theory". The Sociological Quarterly 28 (3): 303-311. doi:10.1111/j.1533$\underline{\text { 8525.1987.tb00296.x }}$

Moses, T. 2009. "Self-Labelling and its Effects among Adolescents Diagnosed with Mental Disorders”. Social Science \& Medicine 68 (3): 570-578.

doi:10.1016/j.socscimed.2008.11.003

Moses, T. 2010. "Being treated differently: Stigma Experiences with Family, Peers, and School Staff among Adolescents with Mental Health Disorders”. Social Science \& Medicine 70 (7): 985-993. doi:10.1016/j.socscimed.2009.12.022

O’Reilly, M., H.C. Taylor, and P. Vostanis. 2009. “"Nuts, Schiz, Psycho”: An Exploration of Young Homeless People's Perceptions and Dilemmas of Defining Mental Health”. Social Science \& Medicine 68 (9): 1737-1744. doi:10.1016/j.socscimed.2009.02.033

Quirk, A., and P. Lelliott. 2001. "What Do we Know about Life on Acute Psychiatric Wards in the UK? A Review on the Research Evidence”. Social Science \& Medicine 53 (12): 1565-1574. doi:10.1016/S0277-9536(00)00457-3 
Quirk, A., P. Lelliott, and Seale, C. 2006. “The Permeable Institution: An Ethnographic Study of Three Acute Psychiatric Wards in London”. Social Science \& Medicine 63 (8): 2105-2117. doi:10.1016/j.socscimed.2006.05.021

Robards, B. 2012. 'Leaving MySpace, joining Facebook: 'Growing up' on Social Network Sites". Journal of Media \& Cultural Studies 26 (3): 385-398. doi: $\underline{10.1080 / 10304312.2012 .665836}$

Rosenhan, D.L. 1973. “On being Sane in Insane Places”. Science 179 (4007): 250-258. doi: $10.1126 /$ science. 179.4070 .250

Scarce, R. 2002. “Doing Time as an Act of Survival”. Symbolic Interaction 25 (3): 303-321. doi: $10.1525 /$ si.2002.25.3.303

Sweeting, H., P. West, R. Young, and G. Der. 2010. “Can We Explain Increases in Young People's Psychological Distress over Time?” Social Science \& Medicine 71 (19): 18911830. doi: $10.1016 /$ j.socscimed.2010.08.012

Whitley, R., and D.R. Campbell. 2014. "Stigma, Agency and Recovery amongst People with Severe Mental Illness”. Social Science \& Medicine 107: 1-8. doi:10.1016/j.socscimed.2014.02.010

Wang, V., and S. Edwards. 2016. "Strangers are Friends I Haven't Met Yet: A Positive Approach to Young People's Use of Social Media”. Journal of Youth Studies, 19 (9): 12041219. doi: $10.1080 / 13676261.2016 .1154933$

Yang, L.H., A. Kleinman, B.G. Link, J.C. Phelan, S. Lee and B. Good. 2007. "Culture and stigma: Adding moral experience to stigma theory”. Social Science and Medicine, vol. 64(2007), pp. 1524-1535.

Yates, S., M. Payne, and S. Dyson. 2009. “Children and Young People in Hospitals: Doing Youth Work in Medical Settings". Journal of Youth Studies 12 (1): 77-92. doi: doi.org/10.1080/13676260802392965 


\section{University Library}

\section{- M M N E R VA A gateway to Melbourne's research publications}

Minerva Access is the Institutional Repository of The University of Melbourne

Author/s:

Kessing, ML;RAVN, S

Title:

"'It feels as if time has come to a standstill": Institutionalised everyday lives among youth with a mental illness'

Date:

2017

Citation:

Kessing, M. L. \& RAVN, S. (2017). '"It feels as if time has come to a standstill":

Institutionalised everyday lives among youth with a mental illness'. Journal of Youth Studies, 20 (8), pp.959-973. https://doi.org/10.1080/13676261.2016.1273523.

Persistent Link:

http://hdl.handle.net/11343/294908 